\title{
REVERSAL OF DELETERIOUS EFFECT OF EXTRACORONAL IN- OFFICE BLEACHING ON SHEAR BOND STRENGTH OF COMPOSITE RESIN TO BLEACHED ENAMEL: EFFECT OF DELAYED RESTORATION AND DIFFERENT ANTIOXIDANTS APPLICATION - IN VITRO STUDY
}

\author{
Reham Mohamad Attia *
}

\begin{abstract}
Objective: The objective of this in - vitro study was to evaluate the effect of different antioxidants in reversal of deleterious effect of bleaching on shear bond strength of composite resin to bleached enamel.

Materials and methods: Seventy bovine incisors were used. The specimens were randomly divided into seven groups (10 specimens each) as follow: Group 1: no bleaching treatment and no antioxidant application. Group 2: bleaching only without antioxidant application and immediate composite resin application after bleaching. Group 3: bleaching only without antioxidant application and delayed composite application (after 2 weeks) of storage. Group 4: bleaching and application of $10 \%$ Alpha-tocopherol. Group 5: bleaching and application of $6 \%$ cranberry extract. Group 6: bleaching and application of $10 \%$ sodium ascorbate. Group 7: bleaching and application of $10 \%$ green tea. $40 \%$ hydrogen peroxide (Opalescence Xtra Boost $40 \%$, Ultradent, South Jourdan, UT, USA) was used. Four antioxidant solutions were prepared. Composite resin Tetric N-Ceram (IvoclarVivadent, Schaan, Liechtenstein) was used. The shear bond strength was measured using a universal testing machine.
\end{abstract}

Results: one-way ANOVA test revealed significant differences in shear bond strength among the tested groups $(\mathrm{p}<0.001)$. Bond strength significantly decreased after bleaching. There was no significant difference in shear bond strength reversed using 10\% Alpha-tocopherol, 10\% sodium ascorbate and $10 \%$ green tea and delayed restoration. Whereas the difference was significant between group 5(6\% cranberry extract) and other antioxidants groups.

Conclusion: The results obtained from the use of antioxidants using (10\% Alpha-tocopherol, $10 \%$ sodium ascorbate and $10 \%$ green tea extract) were approximately the same as the delayed restoration.

KEYWORDS Antioxidants, bleached enamel, composite resins, shear bond strength.

\footnotetext{
* Associate Professor, Faculty of Dentistry Zagazig Universty, Al Sharquia, Zagazig, Egypt
} 


\section{INTRODUCTION}

Currently, there is an increased interest in esthetic dentistry. Vital tooth bleaching had become a prevalent practice, which was considered a safe, widespread, unadventurous and accepted treatment method for management of teeth discoloration ${ }^{(1)}$. Variable concentrations of carbamide peroxide or hydrogen peroxide (HP) are often basic components of bleaching agents ${ }^{(2)}$.

Free radicals as nascent oxygen, per-hydroxyl, superoxide anions and hydroxyl radicals are released as a consequence of hydrogen peroxide decomposition. These resultant free radicals are characterized by high reactivity. So, they extend to electron rich areas of pigments present in the dental tissues. This leads to decomposition of large pigmented molecules which are composed of conjugated double bonds involving oxygen atoms, carbon and nitrogen into smaller less pigmented ones ${ }^{(1,3)}$.

The outcome of bleaching treatment should be well recognized by clinicians and correlated with other dental managements, particularly adhesive esthetic techniques such as orthodontic treatment, composite bonding or laminate veneers, which may be needed to restore the esthetic problems after bleaching ${ }^{(4)}$.

Decreased bond strength of composite restorations is considered as one of the major adverse effects of vital teeth bleaching procedures, because of the existence of peroxide and free oxygen radicals. Presence of free radicals interferes with composite resin polymerization and inhibits the adhesive systems function ${ }^{(5,6)}$

On the other hand, postponing the adhesive procedure from 24 hours to four weeks after bleaching treatment reestablishes the bond strength similar to baseline standards before bleaching treatment. Patients demand to complete all the needed treatment processes as soon as possible ${ }^{(6)}$.

In order to overcome the technical drawbacks related to compromised bond strength after bleaching, different techniques were suggested. These techniques included treating bleached enamel with alcohol prior to restoration, removing the superficial layer of enamel surface, and using adhesives systems with organic solvent ${ }^{(7)}$. Many in-vitro studies showed that bonding procedures of composite resin can be completed directly if the procedure of bleaching is followed by using antioxidants. Numerous antioxidants are available which can reestablish the shear bond strength after bleaching ${ }^{(8-12)}$

Alpha-tocopherol is a very active components of vitamin E complex. It is a potent antioxidant present in the body of human in a lipid phase. Alphatocopherol has an important role as a protective agent against free-radicals action. Free radicals appear in multiple conditions and diseases as aging, different kinds of cancer, circulatory disorders, arthritis, atherosclerosis, cataract, dementia, and finally respiratory diseases persuaded by pollution ${ }^{(13}$, 14). Sodium ascorbate is a biocompatible material, neutral and safe. Its antioxidant effect is observed when applied as a $10 \%$ concentration solution with a time of 10 minutes and it can converse decreased the bond strength of composite resin to enamel after bleaching ${ }^{(15)}$.

Cranberry has bacterial anti-adhesive properties and can help promote health of urinary tract, gastrointestinal tract, and oral cavity. It has antiinflammatory properties that give cardiovascular benefits. In addition; due to its high antioxidant properties, cranberry extract can also protect skin from aging ${ }^{(16)}$. Cranberry is rich in anthocyanins, procyanidins and other active ingredients with obvious antioxidant functions. It has been used in food and pharmaceutical industry for centuries. Procyanidins can effectively remove free radicals, inhibit lipid peroxidation with obvious antioxidant functions ${ }^{(19)}$.

Recently; other natural products can be used as antioxidants like green tea. Camellia sinensis plant is the natural source of green tea ${ }^{(17)}$. It contains 
catechins or flavanols, such as gallocatechin (GC), epicatechin (EC), epigallocatechin (EGC), epigallocatechin gallate (EGCG) and epicatechin gallate (ECG) ${ }^{(18)}$.

Green tea is one of the natural products. It is inexpensive and has a long shelf life. Currently, use of extract of green tea has been investigated in dentistry. Many studies showed that the usage of green tea has the advantage of decreasing erosion of dentin, promoting anti-microbial effects and increasing values of enamel bonding strength following bleaching procedure ${ }^{(20)}$. Green tea catechins exhibited potent and effective antioxidant action and was considered as one of the effective options as antioxidant agent following bleaching ${ }^{(21)}$.

Shear bond test is done by connecting two materials via an adhesive agents. They are loaded in shear till fracture happens. It was the most widely used assessment ${ }^{(22)}$.

The influence of the antioxidants on bleached enamel has been studied only to a limited extent. Bearing in mind the promising properties of cranberry extract in dentistry, the current study was taken on to assess the consequence of application of Alpha-tocopherol, sodium ascorbate, cranberry extract and green tea extract on the shear bond strength of composite resin material to enamel after bleaching procedure.

The null hypothesis was that there was no difference in the reversal of deleterious effect of bleaching on shear bond strength of composite resin to an in - office bleached enamel after the application of 10\% sodium Ascorbate, 10\% Alpha-tocopherol, $10 \%$ green tea and $6 \%$ cranberry solution and delayed restoration after 2 weeks.

\section{MATERIAL AND METHODS}

Seventy bovine incisors were collected directly after slaughter. The collected teeth were sound and free from any developmental defects. Teeth cleaning was done by removing any residual tissue, then pumiced and finally washed using running tap water. Then, the cleaned teeth were stored in distilled water at $+4^{\circ} \mathrm{C}$ till required for the experimental study, a storage time not more than only one week. Since the distilled water was changed daily. The roots of the teeth were detached from the teeth crowns at the $2 \mathrm{~mm}$ apically of cement - enamel junction by a low-speed diamond saw (Isomet ${ }^{\circledR}$, Buehler, Lake Bluff, IL. USA) underneath profuse water spray. The coronal pulp tissue was removed followed by washing the canals in water. The cavity of pulp chamber was occupied by a light body elastomeric impression material (3M EXPRESS ${ }^{\mathrm{TM}}$ XT Light body fast set refill blue, Germany) to prevent diffusion of the self-curing acrylic monomer inside the pulp chamber.

The crowns of the teeth were fixed in a self-cure acrylic resin block (Acrostone, self-cure acrylic resin, Egypt) where the labial surfaces faced up and exposed for further treatment during the study. The samples were preserved in cold water up until the self-cured acrylic resin was thoroughly cured to reduce the thermal action created by the process of curing of the resin. The surface was ground using 600 grit silicon carbide paper under a constant flow of water, to obtain flat enamel surfaces. Under light microscope, the specimens were examined to examine enamel surface and exclude any appearance of dentine.

The specimens were divided randomly into seven groups (10 specimens each) as follows:

- Group 1: no bleaching treatment and no antioxidant application

- Group 2: bleaching only without antioxidant application and immediate composite resin application after bleaching

- Group 3: bleaching only without antioxidant application and delayed composite application (after 2 weeks) of storage

- Group 4: bleaching and application of $10 \%$ Alpha-tocopherol 
- Group 5: bleaching and application of $6 \%$ cranberry extract

- Group 6: bleaching and application of $10 \%$ sodium ascorbate

- Group 7: bleaching and application of $10 \%$ green tea extract

\section{Bleaching procedures:}

$40 \%$ hydrogen peroxide (Opalescence Xtra Boost 40\%, Ultradent, South Jourdan, UT, USA) was used by its application three times to the enamel of labial surfaces of the specimens for 15 minutes according to the manufacturer's instructions. The bleaching material was refreshed each 10 minutes. After accomplishment, the specimens were rinsed with water and air-dried.

\section{Antioxidants preparation:}

Four antioxidant solutions were prepared as follows:

- For preparation of $10 \%$ Alpha-tocopherol: $10 \mathrm{~g}$ of alpha-tocopherol (Sigma Aldrich, Co., Egypt) were diluted in ethyl ethanol to make $10 \%$ solution.

- For preparation of $10 \%$ sodium ascorbate, $10 \mathrm{~g}$ of sodium ascorbate powder (Sigma Aldrich, Co., - Egypt) were dissolved in $50 \mathrm{ml}$ of distilled water and the volume of solution was increased to $100 \mathrm{ml}$ [17].

- Preparation of $6 \%$ cranberry extract: it was prepared using $6 \mathrm{mg}$ of cranberry extract in the form of powder collected from the capsules (cranberry EMA Pharm pharmaceuticals-Egypt) then it was dissolved in $100 \mathrm{ml}$ of distilled water to make $6 \%$ cranberry extract.

- $10 \%$ solution of green tea extract was prepared by dissolving $10 \mathrm{mg}$ of green tea powder (Mepaco green tea multi treat 300mg - Arab Company for Pharmaceuticals \& Medicinal Plants MEPACO-MEDIFOOD - Egypt) in
$100 \mathrm{ml}$ of distilled water to make $10 \%$ green tea extract solution.

After preparation of antioxidant agents, all solutions were refrigerated until included in the study.

All antioxidant solutions were prepared in Pharmacognosy Department, Faculty of Pharmacy, Zagazig University, Egypt.

\section{Antioxidants application:}

Regarding specimens of groups 4,5 ,6 and 7; antioxidant solutions were applied to the surface of specimens using a micro-brush for a period of 10 minutes. Every one minute the solution of antioxidant was refreshed to compensate the evaporation. Then the surfaces of the specimens were rinsed using running water and gently air-dried.

\section{Bonding procedure and composite resin application:} $37 \%$ phosphoric acid gel N-Etch (IvoclarVivadent, Schaan, Liechtenstein) was applied for 20 seconds, followed by rinsing for 30 seconds and then air drying for 10 seconds. After that a thin layer of the adhesive material Tetric N-Bond (IvoclarVivadent, Schaan, Liechtenstein) was applied to the surface of etched enamel, spread lightly using compressed air and then light-cured for 10 seconds. By aiding of split Teflon mold $3 \mathrm{~mm}$ in diameter and $4 \mathrm{~mm}$ in height; a composite resin Tetric N- Ceram (IvoclarVivadent, Schaan, Liechtenstein) were placed in two increments into split Teflon mold and light cured for 20 seconds for each increment. So, the composite restoration was attached to the labial surface of each crown.

Distilled water was used to immerse all the specimens at room temperature for 24 hours to be sure of complete polymerization. Measurement of the shear bond strength was done using a universal testing machine (Model LRX-plus; Lloyd Instruments Ltd., Fareham, UK) at a crosshead speed of $0.5 \mathrm{~mm} /$ minute (figure 1 ). The fractured surfaces of the specimens were inspected and evaluated 
using scanning electron microscopy (SEM) (JEOL JXA-840A scanning microscope, USA) (figure 2). The examined surfaces were subjected to vacuum in a sputter coater (SPI-MOUDULE-Sputter Coater, West Chester, USA) to produce deposition of a thin layer of gold, equivalent to $10 \_6 \mathrm{~mm}$, to increase the enamel surface reflectance.

The obtained shear bond strength values were statistically analysed using SPSS version 20 using ANOVA and Tukey's test; where the level of significance $(\mathrm{P}<0.001)$. The mode of failure was categorized and divided into adhesive failure, cohesive failure and mixed failure.

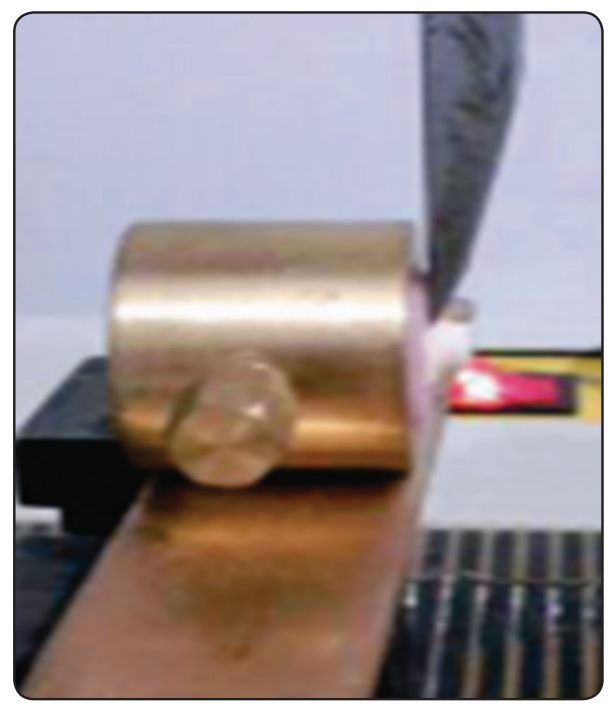

Fig. (1) Shear bond strength test using universal testing machine

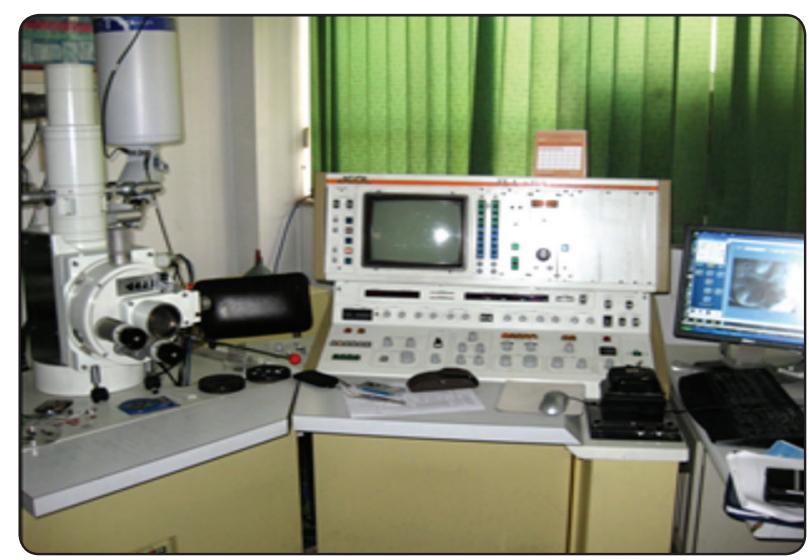

Fig. (2) Scanning electron microscope

\section{RESULTS}

As shown in (table 1) \& (figure 3) one-way ANOVA test revealed significant differences in shear bond strength among the tested groups $(\mathrm{p}<0.001)$. The specimens were immediately restored after bleaching by composite resin, exhibited the lowest shear bond strength among all tested groups (8.469 $\pm 0.366)$. On other hand; group (1) which had no bleaching treatment and no antioxidant application displayed the highest shear bond strength in comparison to other tested groups (19.290 \pm 0.247$)$.

Intergroup comparison using TUKEY'S test revealed significant difference between group (1) and all other tested groups where $(\mathrm{p}<0.001)$. Similarly, this was the same for group (2). The difference was significant between group (2) and all other tested groups. The difference in shear bond strength between group (3) and group (5) was significant whereas the difference between group (3) and groups $(4,6,7)$ was not significant as $(\mathrm{P}=$ $0.066),(\mathrm{P}=0.056)$ and $(\mathrm{P}=0.60)$ respectively.

Regarding group (4); the difference was significant between this group used 10\% Alphatocopherol and group (5) used 6\% cranberry extract after bleaching procedure. However, the difference was not significant when compared with groups (6) and (7) where $(\mathrm{p}=1.000)$. The difference between group (5) and group (6) as well as between group (5) and (7) was significant where $(\mathrm{p}<0.001)$. Finally; the difference between group (6) and group (7) was not significant $(\mathrm{P}=1.000)$.

The fractured surface of de-bonded specimens was examined using scanning electron microscope to detect the mode of failure of the specimens as shown in table 2. Group (1) exhibited $0 \%$ adhesive failure where other specimens showed $40 \%$ cohesive and $6 \%$ mixed type of failure. The adhesive type of failure was noted in $60 \%$ of samples of group (2) where the specimens were restored by composite material immediately after bleaching procedure. In comparison to the failure of the specimens where 
antioxidants were applied after bleaching and before restorative procedure as well as delayed composite restoration, the predominant failures were recorded as cohesive and mixed failure. Figures 4 (a,b, and c) presented representative scanning electron microscope images of different types of mode of failure. And the ratio of each type in each tested group shown in table 2 .

TABLE (1) Mean and standard deviation of shear bond strength values (MPa).

\begin{tabular}{|c|c|c|c|c|c|c|c|c|}
\hline \multirow{3}{*}{$\begin{array}{l}\text { Groups } \\
\text { Group } 1\end{array}$} & \multicolumn{6}{|c|}{ Shear bond strength (Mpa) } & \multicolumn{2}{|c|}{ ANOVA } \\
\hline & \multicolumn{3}{|c|}{ Range } & \multirow{2}{*}{$\begin{array}{c}\text { Mean } \\
19.290\end{array}$} & \multirow{2}{*}{$\begin{array}{l} \pm \\
\pm\end{array}$} & \multirow{2}{*}{$\frac{\text { SD }}{0.247}$} & $\mathbf{F}$ & P-value \\
\hline & 19 & - & 19.6 & & & & \multirow{7}{*}{670.906} & \multirow{7}{*}{$<0.001^{*}$} \\
\hline Group 2 & 8 & - & 9 & 8.469 & \pm & 0.366 & & \\
\hline Group 3 & 17.5 & - & 18.6 & 18.186 & \pm & 0.419 & & \\
\hline Group 4 & 16.5 & - & 18.2 & 17.601 & \pm & 0.582 & & \\
\hline Group 5 & 14.6 & - & 15.6 & 15.208 & \pm & 0.308 & & \\
\hline Group 6 & 16.42 & - & 18.22 & 17.587 & \pm & 0.673 & & \\
\hline Group 7 & 17.07 & - & 18.14 & 17.594 & \pm & 0.366 & & \\
\hline \multicolumn{9}{|c|}{ TUKEY'S Test } \\
\hline & \multicolumn{2}{|l|}{ Group 1} & Group 2 & Group 3 & \multicolumn{2}{|c|}{ Group 4} & Group 5 & Group 6 \\
\hline Group 2 & \multicolumn{2}{|l|}{$<0.001 *$} & & & & & & \\
\hline Group 3 & \multicolumn{2}{|l|}{$<0.001 *$} & \multicolumn{2}{|l|}{$<0.001 *$} & & & & \\
\hline Group 4 & \multicolumn{2}{|l|}{$<0.001 *$} & \multicolumn{2}{|l|}{$<0.001 *$} & & & & \\
\hline Group 5 & \multicolumn{2}{|l|}{$<0.001 *$} & $<0.001 *$ & $<0.001 *$ & \multicolumn{2}{|c|}{$<0.001^{*}$} & & \\
\hline Group 6 & \multicolumn{2}{|l|}{$<0.001 *$} & $<0.001 *$ & 0.056 & \multicolumn{2}{|c|}{1.000} & $<0.001 *$ & \\
\hline Group 7 & \multicolumn{2}{|l|}{$<0.001 *$} & $<0.001 *$ & 0.060 & \multicolumn{2}{|c|}{1.000} & $<0.001 *$ & 1.000 \\
\hline
\end{tabular}

TABLE (2) The mode of failure (fracture surface

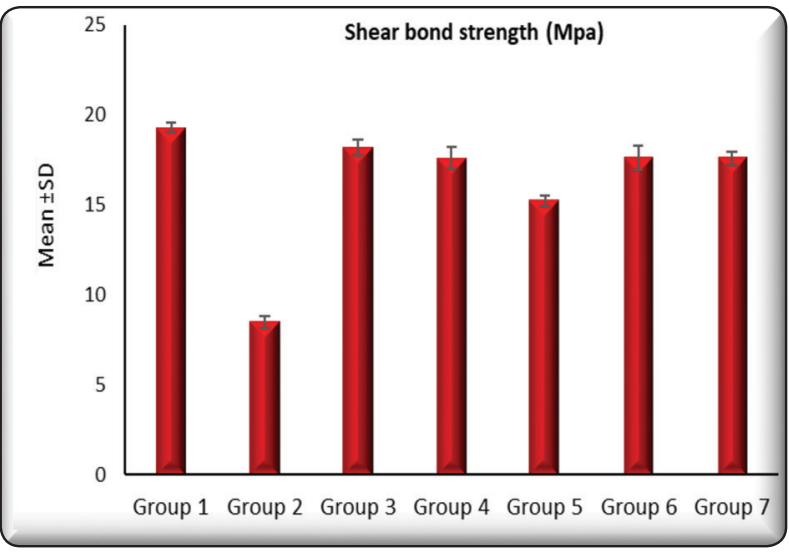

Fig. (3) A bar chart indicates the means and SDs of shear bond strength values (in MPa) of all tested groups analysis) of all tested groups after the shear bond strength test

\begin{tabular}{|c|c|c|c|}
\hline $\begin{array}{c}\text { Mode of failure } \\
\text { Group }\end{array}$ & $\begin{array}{c}\text { Adhesive } \\
\text { failure }\end{array}$ & $\begin{array}{c}\text { Cohesive } \\
\text { failure }\end{array}$ & Mixed \\
\hline Group 1 & $0(0 \%)$ & $4(4 \%)$ & $6(6 \%)$ \\
\hline Group 2 & $6(60 \%)$ & $0(0 \%)$ & $4(40 \%)$ \\
\hline Group 3 & $1(1 \%)$ & $3(3 \%)$ & $6(6 \%)$ \\
\hline Group 4 & $1(1 \%)$ & $2(2 \%)$ & $7(7 \%)$ \\
\hline Group 5 & $3(3 \%)$ & $2(2 \%)$ & $5(5 \%)$ \\
\hline Group 6 & $2(2 \%)$ & $2(2 \%)$ & $6(6 \%)$ \\
\hline Group 7 & $2(2 \%)$ & $2(2 \%)$ & $6(6 \%)$ \\
\hline
\end{tabular}




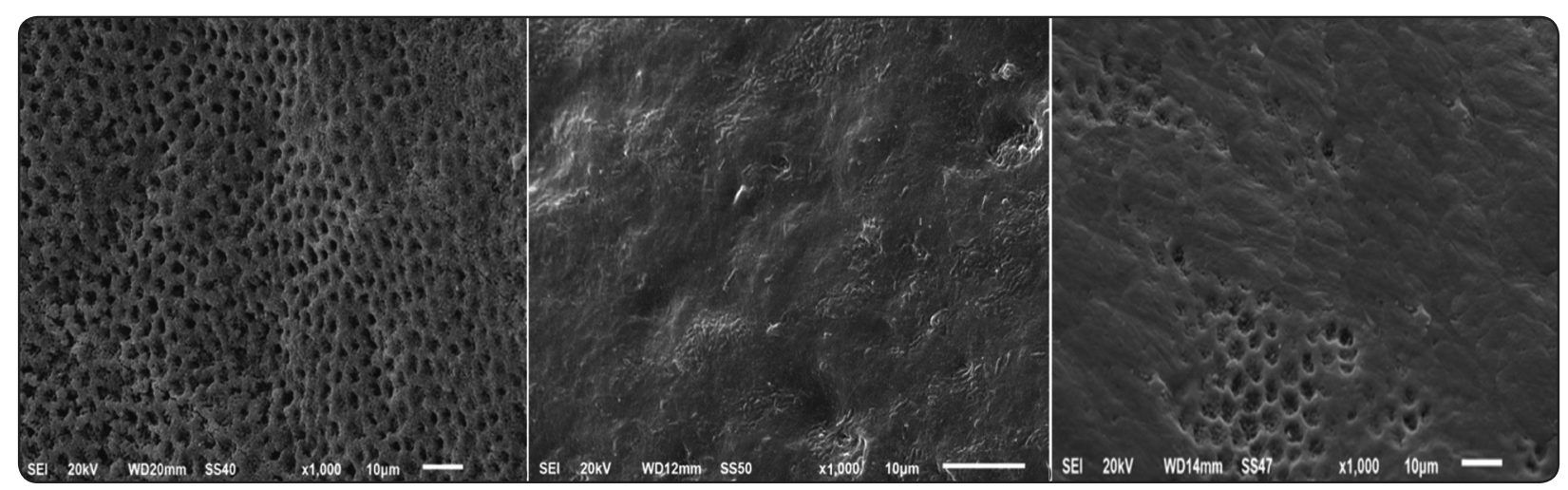

Fig. (4) Scanning electron microscope image of the mixed type of failure (a) Scanning electron microscope image of the adhesive failure type. Honeycomb appearance of etched enamel without resin penetration, (b) Scanning electron microscope image of the cohesive type of failure, (c) Scanning electron microscope image of the mixed type of failure.

\section{DISCUSSION}

Vital bleaching is considered one of the most commonly used effective and conservative modalities of treatment options of discolored teeth. Several studies have shown the effect of bleaching procedures, on hard tissues, and its impact on bonding strength of adhesive restorative materials to the hard tooth structure ${ }^{(23)}$.

Free radical is a molecule that is characterized by having one unpaired electron, providing it high reactivity. These molecules have the ability to react with the electron-rich regions of the pigments inside the dental structure, leading to break down of large pigmented molecules into smaller, less pigmented ones ${ }^{(24)}$.

The diminution in bond strength and the decrease of interaction between the adhesive system and bleached hard teeth structure could be explained by the presence of residual oxygen existence ${ }^{(25)}$. It inhibits polymerization reaction and leads to voids formation at the surface of adhesion and decrease the adaptation of resin material (26). Furthermore, other significant influences are the reduction in calcium content which leads to diminution in microhardness of enamel as well as the changes in the organic content of tooth structure ${ }^{(27)}$. Moreover, the presence of peroxide ions in the bleached enamel leads to formation of resin-bleached enamel inter- face which is characterized by its granular and porous nature with a bubbled look ${ }^{(25,28)}$. Antioxidant agents have been used to inactivate the free radicals ${ }^{29)}$. Preceding studies advocated that the subsurface organic matrix of enamel may be changed via the oxidizing consequence of hydrogen peroxide ${ }^{(30)}$. Lai et al. ${ }^{(31)}$ reported that the changes occurred as a result of bleaching were considered temporary and reversible alterations of hard tooth structure. Because of the adverse effects of bleaching procedure on bond strength of composite resin to enamel; the recommendation was to postpone the restorative procedure from one to two weeks ${ }^{(32)}$. The delay in restorative procedure permitted dispersion of the free radicals from the hard tooth structure and the reoccurrence of the proper and efficient bond strength and hybrid layer comparable to prebleached levels. If the restoration with composite resin took place directly after the bleaching procedure, the strength of the bond and the nature of the hybrid layer at the margin of restoration were markedly decreased ${ }^{(33)}$. Thus; in the current study, different types of antioxidants were used to improve the adversely affected bond strength between bleached enamel and composite resin.

For in-vitro studies, different types of non-human teeth have been used such as bovine, shark equine and primate teeth. Bovine teeth are considered the 
most commonly used. Usage of bovine teeth has many advantages as they can gain in large quantities and they usually come in a good condition without caries or other structural defects. In addition; bovine teeth have a quite large surface area ${ }^{(34-36)}$.

In the current study; bovine teeth were utilized to measure the shear bond strength of bleached enamel with composite resin. Use of bovine teeth is appropriate and acceptable because there was no significant differences in bond strength measurements between bovine and human teeth ${ }^{(37)}$.

In the present study; shear bond strength was used to determine the bonding of composite resin to the bleached enamel. Shear bond strength is considered one of the popular and accurate methods. It is also characterized by the simplicity of preparing the samples and the ease of carrying out the test ${ }^{(38)}$.

Group (1); where neither the bleaching nor the antioxidant was used was considered the control group. The shear bond strength in this group was the highest among all tested groups with significant difference. This result was expected and the reason was that the enamel had all the characteristics that qualify it to form efficient bonds with resinous material. Certainly, this result was compatible with a lot of studies that compared bond strength between bleached and non- bleached enamel. These studies considered non-bleached enamel as a control group and compared the bond strength of it with bleached one even if antioxidants were used ${ }^{(39-44)}$.

In contrast, other studies did not detect a significant difference between bleached and unbleached enamel as reported in an in-vivo study carried by Leonard et al ${ }^{(45)}$ who revealed that a 14day regimen of night guard vital bleaching (NGVB) consuming a $10 \%$ carbamide peroxide had slight outcome and effect on the enamel surface morphology. In addition; another study revealed there was no significant effect of carbamide peroxide with different concentrations on the enamel surface ${ }^{(46)}$. However, it was noted that most studies that did not find a significant difference between bleached and non-bleached enamel, considered only the difference of enamel surface morphology and did not study the bond strength. This could explain the difference between these results and the outcome of present study. Sung et al ${ }^{(47)}$ concluded that the consequence of carbamide peroxide bleaching on bond strength could depend upon the adhesive system and the category of solvent in the adhesives (either alcohol or acetone base). They concluded that alcohol-based bonding agent could diminish or exclude the unfavorable possessions of residual oxygen to the composite resin bonding. So, in the current study, Tetric N-Bond was used where the solvent is ethanol which was provided for easy application in one layer of bonding and this excluded the effect of alcohol in the results.

In the present study, the shear bond strength recorded the lowest value when bleached enamel was restored immediately with composite resin after bleaching without delay and the samples were not treated with antioxidants. This finding was attributed to the inclusion of peroxide ions in enamel as reported in many other studies ${ }^{(48)}$. In addition; the reason of reduced bond strength was not only due to oxygen ions, but also due to the softening of the hard tooth structure by bleaching material. The mode of failure recorded in this group was adhesive failure. So, reduced bond strength was related to reduced cohesive strength of the adhesive layer to enamel ${ }^{(11,31,49-52)}$.

Sharafeddin et al. ${ }^{(53)}$ described that dentin and the dentinal fluid could act as a reservoirs of oxygen and peroxide. These reservoirs of gaseous or dissolved oxygen products may continue until removed by micro-circulation of the pulp and external surface dispersal and diffusion. A greater surface diffusion would be expected based on a reduced pulpal microcirculation. As a result of bleaching; peroxide ions replaced hydroxyl radicals in the apatite lattice, which led to formation of peroxide-apatite. Decomposition of peroxide ions could occur and replace hydroxyl radical re-enter the apatite lattice, which 
led to removal of the changes resulted from integration of peroxide ions. So, in the present study, that waiting period of two weeks led to improve the shear bond strength between composite resin and bleached enamel but the value did not reach the same value of control group (unbleached enamel) (54). The results of this study were in parallel with the results of Cavalli et al ${ }^{(55)}$ where the bond strengths after the first two weeks of bleached enamel to composite resin, were less than that of untreated enamel. Whereas after a delay of three weeks, the bond strength resumed to that of the non-bleached control group. Regarding this point; the results of this study were partially compatible with the findings of NariRatih and Widyastuti ${ }^{(25)}$, where a waiting period of two weeks produced enhancement of the bond strength which was nearly a comparable value of shear bond strength compared to the control nonbleached enamel.

Vitamin E is considered a collective name for a group of powerful, chain-breaking, lipid solvable antioxidants. Vitamin E antioxidant activity is attributed to tocopherols $(\alpha, \beta, \gamma$, and $\delta)$ and four tocotrienols $(\alpha, \beta, \gamma$, and $\delta)$. Alpha-tocopherol is abundantly found in nature and is responsible for the reverse of symptoms related to Vitamin E deficiency in individuals ${ }^{(56)}$. The action of Vitamin $\mathrm{E}$ is on free radicals, which are considered as byproducts resulted from pollutants entered the body and ordinary metabolism. These damaging chemical products lead to destruction of the cell body and could lead to the tumors and cardiovascular disease (57). $10 \%$ alpha-tocopherol was used in present study as antioxidant and it significantly reversed the shear bond strength, which decreased after bleaching with no significant difference when compared with values of shear bond strength of group (3) (delayed composite application). The existence of alcohol in the structure of the $10 \% \alpha$-tocopherol solution prepared for the existing study can be considered one of the reasons for improving the shear bond strength. Moreover, vitamin E has a more oxidizing effect and is more constant and stable than ascorbate due to its hydrophobicity. So, the current results came in coincidence with various other studies ${ }^{(13,14,57,58)}$.

Cranberries and their molecular components have received more attention from researchers in human health for its therapeutic effect on urinary tract infections (UTIs) mainly by acting as a potential anti-adherent agent ${ }^{(59)}$. Recently, attention is being focused on cranberry extracts as a potential therapeutic agent in various other areas of health, including infectious diseases, cancer, and cardiovascular disease ${ }^{(60)}$.

Cranberry extract was used as antioxidant for the reversal of bond strength of bleached enamel as a novel approach and on a small and limited scale. Application of $6 \%$ cranberry extract solution improved the bond strength of bleached enamel as it was higher than that of bleached enamel with significant difference. Nevertheless, the shear bond strength values were less than that recorded for other antioxidant materials as in group (3) with significant difference. The obtained results were compatible with the study carried out by Eggula et al ${ }^{(61)}$ where $10 \%$ sodium ascorbate solution was found to be more effective than $6 \%$ cranberry extract solution but not statistically significant. The divergence in results related to the significant difference between sodium ascorbate solution and cranberries extract solution, may be attributed to the method of antioxidant application. In current study antioxidants were applied using micro-brush, whereas in the Eggula et al study the specimens were immersed in the solution of antioxidants.

Gupta et al ${ }^{(60)}$ suggested that the high-molecular-weight cranberry extract was highly efficacious in reducing the $S$. mutans counts in the oral environment. This feature may be encouraging to use it as antioxidant with additional advantages.

One of the commonly and well-known antioxidant agents is sodium ascorbate. It is capable of decreasing a diversity of oxidative compounds, mainly free radicals. Sodium ascorbate is characterized by low toxicity and it is usually used as an 
antioxidant agent, in the food manufacturing. Ascorbic acid shows great antioxidant effect ${ }^{25)}$. Though, its $\mathrm{pH}$ is about 1.8 , which leads to unsuitable use of it clinically. On the contrary; the acid sodium ascorbate has a $\mathrm{pH}$ of 7.4, and its antioxidant effect is comparable to the ascorbic acid ${ }^{(62)}$.

The antioxidant effect of sodium ascorbate leads to counteract and converse the oxidizing action of the bleaching procedure. Consequently, the changed redox potential of the oxidized bonding substrate is reestablished and adhesive system polymerization takes place properly ${ }^{(63,64)}$.

The results of the current study support these findings. Shear bond strength recorded in group (6) where sodium ascorbate was used as antioxidant improved markedly. The values of shear bond strength showed significant difference compared to unbleached enamels. On the other hand, there was no significant difference between shear bond strength and those of group (3) where composite application delayed after bleaching (after 2 weeks) of storage. The results were in agreement with preceding studies (65-67). On the other hand, the results regarding this group were not compatible with the study carried out by Muraguchi et al ${ }^{(64)}$ who stated that the usage of ascorbic acid as antioxidant to bleached enamel led to improvement of bond strength which was equal to those of non-bleached enamel surface. The dissimilarity may be attributed to the use of an ascorbic acid solution $10 \mathrm{wt} \%$ in the preceding study, while in the current study $10 \%$ sodium ascorbate was used. An ascorbic acid solution possesses an etching effect as it has an acidity about $\mathrm{pH} 2$. So, the bond strength may improve after bleaching due to micromechanical retention to etched hard tooth structures. On the other hand, Savadi et al., showed that the cumulative effect of ascorbic acid and bleached material may lead to increased retention of pathogenic microorganisms in enamel surfaces. Also; Coppla et al ${ }^{(68)}$ found that the use of $35 \%$ sodium ascorbate for twice, 5- and 10-minuts each, was an effective method to retain the micro-shear bond strength between resin composite and bleached enamel to the level of non-bleached enamel. It was clear that the difference in the results of that study compared to the current study was due to the high concentration of sodium ascorbate in addition to the time of its application.

Green tea extract can reverse the reduced shear bond strength. In contrast to the expected result, it recorded comparatively one of the highest shear bond strength values among the used antioxidant materials. The results came in coincide with the previous study conducted by Sharafeddin et $\mathbf{a l}^{(69)}$. In this in-vitro study, it was concluded that, using green tea extract after bleaching exhibited significant increasing outcome on the shear bond strength of resin composite to the bleached enamel after 38\% hydrogen peroxide gel application.

On the other hand, the results of existing study were conflicting with Ozelin et al ${ }^{(70)}$ where it was concluded that the reversal of compromised bond strength obtained by $10 \%$ green tea gel application for 1 hour was not as 10 minutes of application as applied in the current study.

In the current study, despite the obvious effects of application of different antioxidant solutions before bonding procedure which led to enhancement of shear bond strength, its value was significantly increased than the bleached enamel immediately restored with composite. Reversal of shear bond strength was comparable to delayed restoration but lower than that of non-bleached enamel with significant difference. This finding was compatible with Nari-Ratih and Widyastuti ${ }^{(25)}$ who stated that none of the antioxidant agents had capability of wholly and entirely counteracting and reversing the damaging effects of bleaching treatment on bond strength with composite resin.

The fractured surface of the specimens was evaluated using scanning electron microscope and the obtained findings were in agreements with Kaya et al ${ }^{(71)}$ and Nari-Ratih and Widyastuti ${ }^{(25)}$. The mode of failure of the specimens treated with 
antioxidants as well as specimens restored after two weeks were mixed failure (adhesive and cohesive). This finding proved that using antioxidants improved the shear bond strength. The majority of failures of group (2) which were immediately restored were adhesive.

\section{CONCLUSIONS}

Under the limitations of the current study, it can be concluded that:

1. There was a noteworthy decrease in shear bond strength of composite resin to bleached enamel immediately after the bleaching procedure.

2. A delay of two weeks significantly increased bond strength of composite resin to bleached enamel.

3. Shear bond strength of composite resin to bleached enamel can be restored using $10 \%$ Alpha-tocopherol, $10 \%$ green tea, $10 \%$ sodium ascorbate and $6 \%$ cranberry extract.

4. The results obtained from the use of antioxidants using (10\% Alpha-tocopherol, $10 \%$ sodium ascorbate and $10 \%$ green tea extract) is approximately the same as the delayed restoration, without the need to postpone the restorative procedure.

5. Improvement of shear bond strength created by using $10 \%$ Alpha-tocopherol, $10 \%$ sodium ascorbate and $10 \%$ green tea extract was significantly more than that of $6 \%$ cranberry extract.

\section{REFERENCES}

1. Grazioli G, Valente LL, Isolan CP, Pinheiro HA, Duarte CG, Münchow EA. Bleaching and enamel surface interactions resulting from the use of highly-concentrated bleaching gels. Archives of Oral Biology. 2018;87:157-62.

2. Kutuk ZB, Ergin E, Cakir FY, Gurgan S. Effects of inoffice bleaching agent combined with different desensitizing agents on enamel. Journal of Applied Oral Science. 2019;27.
3. Malpani S, Shiraguppi VL, Deosarkar B, Das M, Nagargoje G, Gadge P. BLEACHING OF DISCOLORED TEETH: A REVIEW. Journal of Interdisciplinary Dental Sciences. 2019;8(1):15-22.

4. Joiner A. The bleaching of teeth: a review of the literature. Journal of dentistry. 2006;34(7):412-9.

5. Shah V, Patel M, Bhavsar B. An in vitro comparative evaluation of various newer bonding agents on bond strength of bleached enamel treated with an antioxidant. IOSR-JDMS. 2018;17:50-3.

6. Kılınç Hİ, Aslan T, Kılıç K, Er Ö, Kurt G. Effect of delayed bonding and antioxidant application on the bond strength to enamel after internal bleaching. Journal of Prosthodontics. 2016;25(5):386-91.

7. Niat AB, Yazdi FM, Koohestanian N. Effects of drying agents on bond strength of etch-and-rinse adhesive systems to enamel immediately after bleaching. Journal of Adhesive Dentistry. 2012;14(6).

8. Abraham S, Ghonmode WN, Saujanya K, Jaju N, Tambe VH, Yawalikar PP. Effect of grape seed extracts on bond strength of bleached enamel using fifth and seventh generation bonding agents. Journal of international oral health: JIOH. 2013;5(6):101

9. Bulut H, Turkun M, Kaya AD. Effect of an antioxidizing agent on the shear bond strength of brackets bonded to bleached human enamel. American Journal of Orthodontics and Dentofacial Orthopedics. 2006;129(2):266-72.

10. Vidhya S, Srinivasulu S, Sujatha M, Mahalaxmi S. Effect of grape seed extract on the bond strength of bleached enamel. Operative dentistry. 2011;36(4):433-8.

11. Rana R, Kaushik M, Sharma R, Reddy P, Mehra N. Comparative evaluation of effects of natural antioxidants on the shear bond strength of composite resin to bleached enamel. Indian Journal of Dental Research. 2019;30(1):112.

12. Ergün Kunt G, Yılmaz N, Şen S, Dede Dö. Effect of antioxidant treatment on the shear bond strength of composite resin to bleached enamel. Acta odontologica Scandinavica. 2011;69(5):287-91.

13. Kavitha M, Selvaraj S, Khetarpal A, Raj A, Pasupathy S, Shekar S. Comparative evaluation of superoxide dismutase, alpha-tocopherol, and $10 \%$ sodium ascorbate on reversal of shear bond strength of bleached enamel: An in vitro study. European journal of dentistry. 2016;10(01):109-15.

14. Thapa A, Vivekananda PA, Thomas MS. Evaluation and comparison of bond strength to $10 \%$ carbamide peroxide bleached enamel following the application of $10 \%$ and 
$25 \%$ sodium ascorbate and alpha-tocopherol solutions: An in vitro study. Journal of conservative dentistry: JCD. 2013;16(2):111.

15. Kimyai $\mathrm{S}$, Valizadeh $\mathrm{H}$. The effect of hydrogel and solution of sodium ascorbate on bond strength in bleached enamel. Operative dentistry. 2006;31(4):496-9.

16. Bonifait L, Grenier D. Cranberry polyphenols: potential benefits for dental caries and periodontal disease. Journal (Canadian Dental Association). 2010;76:a130-a.

17. Vishnoi H, Bodla RB, Kant R. Green Tea (Camellia sinensis) and its antioxidant property: A review. Int $\mathrm{J}$ Pharm Sci Res. 2018;9(5):1723-36.

18. Saeed M, Naveed M, Arif M, Kakar MU, Manzoor R, Abd El-Hack ME, et al. Green tea (Camellia sinensis) and 1-theanine: Medicinal values and beneficial applications in humans-A comprehensive review. Biomedicine \& Pharmacotherapy. 2017;95:1260-75.

19. Bansal M, Kaur P, Cyriac A, Kadian N, Jaiswal P, Rathee $\mathrm{K}$. Impact of $\mathrm{J}$ different antioxidants on the bond strength of resinbased composite on bleached enamel-an in vitro study. Contemp Dent Pract. 2019;20(1):64-70.

20. Al-Hassani AA, Al-Shamma AM. Effect of delayed bonding and different antioxidants on composite restoration microleakage of internally bleached teeth. Adv Dent Oral Health. 2018;9.

21. Musial C, Kuban-Jankowska A, Gorska-Ponikowska M. Beneficial Properties of Green Tea Catechins. International Journal of Molecular Sciences. 2020;21(5):1744.

22. Sirisha K, Rambabu T, Ravishankar Y, Ravikumar P. Validity of bond strength tests: A critical review-Part II. Journal of conservative dentistry: JCD. 2014;17(5):420.

23. Yadav S. Bleaching effectiveness and tooth sensitivity of inoffice hydrogen peroxide containing titanium dioxide based bleaching agent: a systematic review. J Dent Sci. 2017;5:96-101.

24. Joshi SB. An overview of vital teeth bleaching. Journal of Interdisciplinary Dentistry. 2016;6(1):3 .

25. Nari-Ratih D, Widyastuti A. Effect of antioxidants on the shear bond strength of composite resin to enamel following extra-coronal bleaching. Journal of clinical and experimental dentistry. 2019;11(2):e126.

26. Nair R, Bandhe S, Ganorkar OK, Saha S, Sial S, Nair A. A comparative evaluation of the three different antioxidant treatments on the bond strength of composite resin to bleached enamel: An in vitro study. Journal of conservative dentistry: JCD. 2019;22(1):82.
27. Rodrigues F, Serro A, Polido M, Ramalho A, FigueiredoPina C. Effect of bleaching teeth with hydrogen peroxide on the morphology, hydrophilicity, and mechanical and tribological properties of the enamel. Wear. 2017;374:21-8.

28. Whang H-J, Shin D-H. Effects of applying antioxidants on bond strength of bleached bovine dentin. Restorative dentistry \& endodontics. 2015;40(1):37-43.

29. Türkmen C, Güleryüz N, Atali P. Effect of sodium ascorbate and delayed treatment on the shear bond strength of composite resin to enamel following bleaching. Nigerian journal of clinical practice. 2016;19(1):91-8.

30. Hegedüs C, Bistey T, Flora-Nagy E, Keszthelyi G, Jenei A. An atomic force microscopy study on the effect of bleaching agents on enamel surface. Journal of dentistry. 1999;27(7):509-15.

31. Lai S, Tay F, Cheung G, Mak Y, Carvalho R, Wei S, et al. Reversal of compromised bonding in bleached enamel. Journal of Dental Research. 2002;81(7):477-81.

32. Feiz A, Mosleh H, Nazeri R. Evaluating the effect of antioxidant agents on shear bond strength of toothcolored restorative materials after bleaching: a systematic review. Journal of the mechanical behavior of biomedical materials. 2017;71:156-64

33. Oz FD, Kutuk ZB. Effect of various bleaching treatments on shear bond strength of different universal adhesives and application modes. Restorative Dentistry \& Endodontics . 2018;43(2).

34. Arango-Santander S, Montoya C, Pelaez-Vargas A, Ossa EA. Chemical, structural and mechanical characterization of bovine enamel. Archives of Oral Biology. 2020; 109:104573.

35. Moda MD, Fagundes TC, Bresciani E, Briso ALF, Dos Santos PH. Comparison of in vitro erosion protocols in bovine teeth to simulate natural erosion lesion: analysis of mechanical properties and surface gloss. Journal of Applied Oral Science. 2019;27.

36. Soares F, Follak A, Da Rosa L, Montagner A, Lenzi T, Rocha R. Bovine tooth is a substitute for human tooth on bond strength studies: A systematic review and metaanalysis of in vitro studies. Dental Materials. 2016; 32(11):1385-93.

37. de Carvalho MFF, Leijôto-Lannes ACN, Rodrigues MCNd, Nogueira LC, Ferraz NKL, Moreira AN, et al. Viability of bovine teeth as a substrate in bond strength tests: a systematic review and meta-analysis. J Adhes Dent. 2018;20(06):471-9. 
38. Lindemuth JS, Hagge MS. Effect of universal testing machine crosshead speed on the shear bond strength and bonding failure mode of composite resin to enamel and dentin. Military medicine. 2000;165(10):742-6.

39. Khamverdi Z, Khadem P, Soltanian A, Azizi M. In-vitro evaluation of the effect of herbal antioxidants on shear bond strength of composite resin to bleached enamel. Journal of Dentistry (Tehran, Iran). 2016;13(4):244.

40. Cheng Y-1, Musonda J, Cheng H, Attin T, Zheng M, Yu H. Effect of surface removal following bleaching on the bond strength of enamel. BMC oral health. 2019;19(1):1-6.

41. Najafi HZ, Bagheri R, Pakshir HR, Tavakkoli MA, Torkan S. Effect of different surface treatment on the shear bond strength of metal brackets to bleached and desensitized enamel. International orthodontics. 2019;17(1):73-9.

42. Xu Y, Zhou J, Tan J. Use of grape seed extract for improving the shear bond strength of total-etching adhesive to bleached enamel. Dental materials journal. 2018;37(2):325-31.

43. Surmelioglu D, Ozdemir Z, Atilan S, Yeniceri N. Effect of surface flattening and phototherapy on shear bond strength immediately after bleaching with different modes of universal adhesive. Nigerian Journal of Clinical Practice. 2020;23(1):110.

44. Zhang H, Shao S, Du A, Wang Y, Cheng B, Zhang Z. Comparative evaluation of two antioxidants on reversing the immediate bond strength of bleached enamel: In vitro study. Medical Science Monitor: International Medical Journal of Experimental and Clinical Research. 2020;26:e920481-1.

45. Leonard Jr RH, Eagle JC, Garland GE, Matthews KP, RUDD AL, PHILLIPS C. Nightguard vital bleaching and its effect on enamel surface morphology. Journal of esthetic and restorative dentistry. 2001;13(2):132-9.

46. 46. Oltu Ü, Gürgan S. Effects of three concentrations of carbamide peroxide on the structure of enamel. Journal of oral rehabilitation. 2000;27(4):332-40.

47. Sung E, Chan S, Mito R, Caputo A. Effect of carbamide peroxide bleaching on the shear bond strength of composite to dental bonding agent enhanced enamel. The Journal of prosthetic dentistry. 1999;82(5):595-9.

48. Rose RC, Bode AM. Biology of free radical scavengers: an evaluation of ascorbate. The FASEB journal. 1993;7(12):1135-42.

49. Rotstein I. Role of catalase in the elimination of residual hydrogen peroxide following tooth bleaching. Journal of Endodontics. 1993;19(11):567-9.
50. Barghi N, GODWIN JM. Reducing the adverse effect of bleaching on composite-enamel bond. Journal of Esthetic and Restorative Dentistry. 1994;6(4):157-61.

51. Lai S, Mak Y, Cheung G, Osorio R, Toledano M, Carvalho $\mathrm{R}$, et al. Reversal of compromised bonding to oxidized etched dentin. Journal of Dental Research. 2001;80(10):1919-24.

52. Azizi F, Bahrami K, Imani MM, Golshah A, Safari-Faramani R. Effect of bleaching with carbamide peroxide on shear bond strength of orthodontic brackets: A meta-analysis of in vitro studies. International Orthodontics. 2020.

53. Sharafeddin F, Motamedi M, Modiri S. Effect of immediate application of pomegranate peel, grape seed and green tea extracts on composite shear bond strength of in-office bleached enamel. Res J Biol Sci. 2013;8:83-7.

54. Sharafeddin F, Farshad F. The effect of aloe vera, pomegranate peel, grape seed extract, green tea, and sodium ascorbate as antioxidants on the shear bond strength of composite resin to home-bleached enamel. Journal of Dentistry. 2015;16(4):296.

55. Cavalli V, Reis A, Giannini M, Ambrosano G. The effect of elapsed time following bleaching on enamel bond strength of resin composite. Operative dentistry. 2001;26(6): 597-602.

56. Brigelius-Flohé R, Traber MG. Vitamin E: function and metabolism. The FASEB Journal. 1999;13(10):1145-55.

57. Sasaki R, Flório F, Basting R. Effect of $10 \%$ sodium ascorbate and $10 \% \alpha$-tocopherol in different formulations on the shear bond strength of enamel and dentin submitted to a home-use bleaching treatment. Operative dentistry. 2009;34(6):746-52.

58. Gogia H, Taneja S, Kumar M, Soi S. Effect of different antioxidants on reversing compromised resin bond strength after enamel bleaching: An in vitro study. Journal of conservative dentistry: JCD. 2018;21(1):100.

59. Raz R, Chazan B, Dan M. Cranberry juice and urinary tract infection. Clinical infectious diseases. 2004;38(10):1413-9.

60. Gupta A, Bansal K, Marwaha M. Effect of high-molecular-weight component of Cranberry on plaque and salivary Streptococcus mutans counts in children: An in vivo study. Journal of Indian Society of Pedodontics and Preventive Dentistry. 2015;33(2):128.

61. Eggula A, Pranitha V, Dwijendra K, Nagarjuna G, Shaik N, Fatima M. Reversal of Compromised Bond Strength of Bleached Enamel Using Cranberry Extract as an Antioxidant: an In Vitro Study. Cureus. 2019;11(11). 
62. de França Perazzo M, Wons ICdSM, Alves HFC, dos Santos Marques JL, Ribeiro AIAM, dos Santos KSA. In vitro evaluation of the effect of antioxidants on the bond strength of bleached teeth. Arquivos em Odontologia. 2017;53.

63. Bulut H, Kaya A, Turkun M. Tensile bond strength of brackets after antioxidant treatment on bleached teeth. The European Journal of Orthodontics. 2005;27(5):466-71.

64. Muraguchi K, Shigenobu S, Suzuki S, Tanaka T. Improvement of bonding to bleached bovine tooth surfaces by ascorbic acid treatment. Dental materials journal. 2007;26(6):875-81.

65. Alencar MS, Bombonatti JFS, Maenosono RM, Soares AF, Wang L, Mondelli RFL. Effect of two antioxidants agents on microtensile bond strength to bleached enamel. Brazilian Dental Journal. 2016;27(5):532-6.

66. Murad CG, Andrade SNd, Disconzi LR, Munchow EA, Piva E, Pascotto RC, et al. Influence of $10 \%$ sodium ascorbate gel application time on composite bond strength to bleached enamel. Acta biomaterialia odontologica Scandinavica. 2016;2(1):49-54.
67. Ghaleb M, Orsini G, Putignano A, Dabbagh S, Haber G, Hardan L. The Effect of Different Bleaching Protocols, Used with and without Sodium Ascorbate, on Bond Strength between Composite and Enamel. Materials. 2020;13(12):2710.

68. Coppla F-M, Freire A, Bittencourt B, Armas-Vega A, Benítez V-E-B, Calixto A-L, et al. Influence of simplified, higher-concentrated sodium ascorbate application protocols on bond strength of bleached enamel. Journal of Clinical and Experimental Dentistry. 2019;11(1):e21.

69. Sharafeddin F, Farshad F, Azarian B, Afshari A. Effect of green tea extract as antioxidant on shear bond strength of resin composite to in-office and home-bleached enamel. Journal of Dental Biomaterials. 2016;3(3):269.

70. Ozelin AA, Guiraldo RD, Carvalho RVd, Lopes MB, Berger SB. Effects of green tea application time on bond strength after enamel bleaching. Brazilian dental journal. 2014;25(5):399-403.

71. Kaya AD, Türkün M, Arici M. Reversal of compromised bonding in bleached enamel using antioxidant gel. Operative dentistry. 2008;33(4):441-7. 